\title{
Economic Design and Evaluation of Feasible Cost Model for Attribute Sampling Tightened-Normal-Tightened Plan
}

\author{
M. Kokila ${ }^{1^{*}}$, K. Pradeepa Veerakumari ${ }^{2}$ \\ ${ }^{1}$ Department of Statistics, Bharathiar University, Coimbatore, Tamil Nadu, India \\ ${ }^{2}$ Department of Statistics, Bharathiar University, Coimbatore, Tamil Nadu, India \\ *Corresponding Author: bayestat@yahoo.com, Tel.: 09443937722
}

Available online at: www.isroset.org

Accepted 04/Aug/2018, Online 30/Aug/2018

\begin{abstract}
Tightened-normal-tightened (TNT) plans are the most useful plans in compliance sampling especially for safety related products. In this scenario the acceptance number zero is desirable. This paper provides the feasible costs model considering the stochastic transition of states while inspecting or in various costs involved in the destructive and non-destructive testing. It reveals the cost behavior with respect to plan parameters through sensitivity analysis and cost curves deals with determining the optimal plan parameters for certain attribute sampling schemes.
\end{abstract}

Keywords-TNT plan, Destructive testing, Non-destructive testing, Optimal inspection plan, Compliance sampling, Sampling plan

\section{INTRODUCTION}

A prime factor for the construction of industrial acceptance sampling plans is a consumer protection. Thus $\mathrm{c}=0$ attribute sampling plans is due to the importance of consumer protection to various fields that are sensitive to the threat of lawsuit from customers whom harmed by nonconforming product. Furthermore, customer satisfaction is paramount to the withholding of market share in a global economy, so compliance sampling plays a vital part and there is a need to demonstrate the effectiveness of sampling schemes for compliance testing. In tightened-normaltightened (TNT) plans presented by Calvin [2] are particularly appropriate for use in compliance sampling as well as in other areas of acceptance control. Plans for verification of quality levels should be capable of demonstrating compliance to stated levels in as economic a manner as possible. Duncan [4] pointed out that the National Highway Traffic Safety Administration to eliminate an acceptance number of $\mathrm{c}=3$. The permissible failure rates raise difficult problems of interpretation and enforcement then there would be $100 \%$ conformance for the lot to pass. Hsu $[8,9]$ developed skip-lot cost model for both destructive and non-destructive sampling which gave optimum plan that minimizes the average cost per good unit. Soundararajan and Vijayaraghavan [16] designed and selected the tightenednormal-tightened scheme indexed by IQL, AQL, AOQL and relative slopes of the OC curve. Suresh and Balamurali [17] given the procedure for the construction and selection of
Tightened-Normal-Tightened (TNT) plans indexed by MAPD. Senthilkumar and Muthuraj [18] constructed for easy selection of the TNT scheme $\left(\mathrm{n}_{1}, \mathrm{n}_{2} ; \mathrm{k}\right)$ by variables. Schemes determined by this method have smaller sample size providing the required information to accept or reject the lot for given two quality levels (AQL, $1-\alpha)$ and (LQL, $\beta$ ). Balamurali and Jun [1] applied Markov chain method for SkSP-V for reducing inspection and provides an economic design to reduce cost. Singh and Sanvalia [19] provides expression for evaluating $\mathrm{OC}, \mathrm{k}, \mathrm{AOQ}$ and $\mathrm{n}$ using single sampling plan for variables under exponentially weighted moving average model. Walse et. al. [20] uses the suitable proximity measure in data mining to select optimal clustering model to solve problems.

Fallahnezhad and Aslam [5] proposed an economical design for the optimal decision using the Bayesian inference along with backward induction is utilized to analyze the expected cost of different decisions. Chen.et.al. [3] including the Taguchi's quadratic quality loss of conforming products associated with raw material and production process sustains the optimal parameters under the minimization of the expected total relevant cost of product per unit time. Pradeepa Veerakumari and Kokila [12] elaborates the structural network which has its stochastic nature is developed for this skip-lot sampling plan-2 (SkSP-2) and SkSP-3 with the Graphical Evaluation Review Technique (GERT) helps in inspection reduction and also economically optimal. In this paper an attempt has been made for TNT 
plans to model an appropriate function for the expected costs having two acceptance probabilities of lots involving switching rules with different state of quality to minimize the expected costs which favors producer and also consumer.

The rest of this paper is organized as follows. In the next Section II the definitions and brief note are described. Section III contains the methodology, expressions, some measures and notations. Section IV contains numerical illustration, sensitivity analysis, results and discussion is expressed by figures and tables to obtain the optimal solution with respect to the cost parameter for the plan. Section V presents the conclusion of research work with future directions.

\section{DEFINITIONS AND BRIEF NOTE}

Tightened-Normal-Tightened sampling schemes of type TNT - $\left(n_{1}, n_{2}, c\right)$ :

When the forthcoming product is in a steady stream of lots, it is an indicative of a continuing process. The small size of sample is justified due to the costly nature of testing; a safety related sampling scheme, the tightened-normal-tightened (TNT) plans proposed by Calvin [1], maintains the same acceptance number for the tightened and normal plans while varying the sample size between them. The tightenednormal-tightened sampling scheme is specified by the parameters $\mathrm{n}_{1}, \mathrm{n}_{2}\left(\mathrm{n}_{1}>\mathrm{n}_{2}\right), \mathrm{c}_{\mathrm{T}}, \mathrm{c}_{\mathrm{N}}, \mathrm{s}$ and $\mathrm{t}$, constitute the criteria for switching to tightened and normal inspection.

The schemes are applied as follows:

1. Start with tightened inspection with the larger sample size $\mathrm{n}_{1}$ and the acceptance number $\mathrm{c}_{\mathrm{T}}=0$.

2. Switch to normal inspection when t lots in a row are accepted under tightened inspection.

3. Inspect using normal inspection with the smaller sample size $\mathrm{n}_{2}$, having acceptance number $\mathrm{c}_{\mathrm{N}}=0$.

4. Even after a rejection if an additional lot 2 out of 5 lots are rejected in the next $\mathrm{s}$ lots, switch to tightened inspection.

5. Go to step 2 .

The probability of acceptance of the TNT plan according to Calvin (1977) shows the scheme to be

$$
\operatorname{Pa}(\mathrm{p})=\frac{P_{1}\left(1-P_{2}^{S}\right)\left(1-P_{1}^{t}\right)\left(1-P_{2}\right)+P_{2} P_{1}^{t}\left(1-P_{1}\right)\left(2-P_{2}^{S}\right)}{\left(1-P_{2}^{S}\right)\left(1-P_{1}^{t}\right)\left(1-P_{2}\right)+P_{1}^{t}\left(1-P_{1}\right)\left(2-P_{2}^{S}\right)}
$$

where $P_{1}$ is the probability of accepting the lot under the tightened inspection and $P_{2}$ is the probability of accepting the lot under the normal inspection. According to Schilling [14], the TNT schemes counterpart the normal - tightened plans of MIL-STD-105D [10] when the switching criteria are set at $t=5$ and $s=4$. Govindaraju and Subramani [6] proposed a methodology for TNT sampling schemes with minimum sum of producer's and consumer's risks for specified sets of values of AQL and LQL and tables are provided for different parameters of such schemes. Soundararajan and Vijayaraghavan [16] observed that the OC curve of a TNT scheme $\left(n_{1}, n_{2}, c\right)$ has a desirable shape for the case where $s=4$ and $t=5$. Thus the economic design and evaluation of Tightened-normal-tightened schemes are presented in the section III.

\section{Methodology AND Measures}

\section{Designing of Tightened-Normal-Tightened Plan:}

Duncan [4] pointed out that the permissible failure rates raise difficulty in the interpretation and enforcement then there would be $100 \%$ conformance for the lot to pass. In order to avoid these problems Duncan eliminate the acceptance number $\mathrm{c}=3$. Thus the Tightened-normal-tightened schemes came into existence to demonstrate the effectiveness of sampling schemes for compliance testing. The working rule is based on switching rules of MIL-STD-105D [10] and Calvin [2] proposed TNT sampling scheme with two sample sizes and same acceptance number involving normal and tightened inspection. Soundararajan and Vijayaraghavan [16] observed that the OC curve of a TNT scheme and developed plan $\left(n_{1}, n_{2}, c\right)$ using single sampling plan for tightened inspection and normal inspection with different sample size and acceptance number other than zero. Suppose there may be two states $\mathrm{k}$ and $\mathrm{j}$ in the production process where in inspection lot during switching process the one is good state $\mathrm{k}$ having very least proportion defective and the other proportion defective are considered as the degraded state $\mathrm{j}$. To address the incidence of such transition of states during the production process the cost model has been developed and the inspection carried out under the TNT scheme under the conditions that the incoming quality follows Poisson distribution is proposed through single sampling plan as reference plan.

The TNT with SSP under the conditions of Poisson distribution as reference plan is operated by combining the stochastic nature of transition of state to sentence the individual lots. The incoming quality is portrayed with confidence levels of transition of states and it is incorporated in the SSP under the conditions of Poisson distribution with parameter $\lambda<5$.

The Operating Procedure for SSP by attributes is as follows,

i. Take a sample of $(n)$ units at random from a lot of size $(N)$

ii. Determine the total number of defective units $X^{T}$ ( $\mathrm{T}$ refers to total).

iii. If $X^{T}$ does not exceed the critical value $c$ accept the lot, otherwise reject the lot.

The OC function of SSP is defined as, 


$$
P_{a}(p)=P[x \leq c]
$$

Here $p$ symbolizes the lot proportion defectives. Schilling [14] also prescribes out that when $n / N \leq 0.10, n$ is large and when $\mathrm{p}<0.1$ such that $n p<5$, then Poisson distribution offers great advantages theoretical as well as numerical, since the two parameters $\mathrm{n}$ and $\mathrm{p}$ are replaced by the one parameter $\lambda=\mathrm{np}$. In general, the values of $P_{a}(p)$, the probability of accepting the lot can be determined on two states of $p$ using the probability models (Poisson model). The probability of acceptance under Poisson model for the single sampling plan is given by,

$$
P_{a}(p)=\sum_{x=0}^{c} \frac{e^{-n p}(n p)^{x}}{x !}
$$

The single sampling plan is used as a reference plan for the existing sampling scheme. In the production process, the lot are submitted for inspection in the order of their production process. There may be two states $\mathrm{k}$ and $\mathrm{j}$ where there are changes in the process fraction defective when the lots are produced in each inspection interval observed from the past records. There may be transition from one state to another per lot. Then the mean of the rare event $\mathrm{np}$ may be altered. In such situation the above mentioned probability distributions fail to study this kind of transition.

In the equation (3) $\mathrm{np}$ is replaced by considering risks $\mathrm{np}(1-\alpha)$ for good state $\mathrm{k}, \delta_{\mathrm{k}}=0.01$ (lot proportion defective) and $n p \beta$ for degraded state $\mathrm{j}, \delta_{\mathrm{j}}=0.10$ without violating the assumptions of Poisson distribution. Thus, the probability distribution for number of defectives under Poisson model for the SSP is given by,

$$
\begin{aligned}
& P_{1}=P_{a}\left(\delta_{k}\right)=\sum_{x=0}^{c} \frac{e^{-n_{1} \delta_{k}(1-\alpha)}\left(n_{1} \delta_{k}(1-\alpha)\right)^{x}}{x !}, P_{2}=P_{a}\left(\delta_{k}\right)=\sum_{x=0}^{c} \frac{e^{-n_{2} \delta_{k}(1-\alpha)}\left(n_{2} \delta_{k}(1-\alpha)\right)^{x}}{x !} \\
& P_{1}=P_{a}\left(\delta_{j}\right)=\sum_{x=0}^{c} \frac{e^{-n_{1} \delta_{j} \beta}\left(n_{1} \delta_{j} \beta\right)^{x}}{x !}, P_{2}=P_{a}\left(\delta_{j}\right)=\sum_{x=0}^{c} \frac{e^{-n_{2} \delta_{j} \beta}\left(n_{2} \delta_{j} \beta\right)^{x}}{x !}
\end{aligned}
$$

$\mathrm{P}_{1}$ and $\mathrm{P}_{2}$ is the probability of acceptance of lot under tightened and normal inspection with lot quality $\mathrm{p}$ is in a good state k exist respectively in equation (4).

In equation (5) $\mathrm{P}_{1}$ and $\mathrm{P}_{2}$ is the probability of acceptance of lot under tightened and normal inspection with lot quality $\mathrm{p}$ in a degrade state $\mathrm{j}$ exist respectively. Hence the probability of acceptance on different state $\mathrm{P}_{1}$ and $\mathrm{P}_{2}$ are obtained using equation (4) and (5) for given values of $n, c$ and $\delta_{\mathrm{k}}$ and $\delta_{\mathrm{j}}$,

The probability of acceptance of the TNT plan on different state $\mathrm{k}$ and $\mathrm{j}$ according to Calvin [2] shows the scheme to be

$$
\begin{aligned}
P a_{k} & =\frac{P_{1}\left(1-P_{2}^{S}\right)\left(1-P_{1}^{t}\right)\left(1-P_{2}\right)+P_{2} P_{1}^{t}\left(1-P_{1}\right)\left(2-P_{2}^{S}\right)}{\left(1-P_{2}^{S}\right)\left(1-P_{1}^{t}\right)\left(1-P_{2}\right)+P_{1}^{t}\left(1-P_{1}\right)\left(2-P_{2}^{S}\right)} \\
P a_{j} & =\frac{P_{1}\left(1-P_{2}^{S}\right)\left(1-P_{1}^{t}\right)\left(1-P_{2}\right)+P_{2} P_{1}^{t}\left(1-P_{1}\right)\left(2-P_{2}^{S}\right)}{\left(1-P_{2}^{S}\right)\left(1-P_{1}^{t}\right)\left(1-P_{2}\right)+P_{1}^{t}\left(1-P_{1}\right)\left(2-P_{2}^{S}\right)}
\end{aligned}
$$

can be calculated further using the probability of acceptance obtained from equation (6) and (7) for given values of $n, c$ and $\delta_{\mathrm{k}}$ and $\delta_{\mathrm{j}}$,

This implies that TNT with SSP under the conditions of Poisson distribution as reference plan is specified by following parameters,

i. SSP under the conditions of Poisson distribution parameters $n, c, \delta_{\mathrm{k}}$ and $\delta_{\mathrm{j}}$,

ii. Tightened and normal probabilities of acceptance $P_{l}$ and $P_{2}$ on different states.

iii. Tightened and normal acceptance numbers say $c=0$ for both inspection.

The OC function of TNT with SSP under the conditions of Poisson distribution as reference plan is defined as given in equation (6) and (7) where $P a_{k}$ and $P a_{j}$ are probabilities of acceptance of the lots under the tightened and normal inspections which is determined for their corresponding acceptance numbers $c=0$ helps the producer and the consumer economically and also quality of the product is up to the satisfactory level.

\section{Conditions for application:}

1. Production of the lots is steady are broadly indicative of the continuing process.

2. Lots are submitted substantially in the order of production.

3. Inspection is by attributes with stable quality.

\section{Glossary and Notations:}

$\mathrm{Cm} \quad$ unit production cost.

$\mathrm{Ci} \quad$ unit inspection cost.

$c_{k} \quad$ cost for inspection and reset.

$c_{d} \quad$ failure costs for shipped discrepant units

$c_{r} \quad$ costs for replacing shipped discrepant units including production costs of replacement, penalty, and expenses for handling found in sampling and screening.

$\mathrm{N}$ number of items in the lot.

$\mathrm{n}$ number of items taken for inspection.

$\delta_{\mathrm{k}} \quad$ lot being proportion defective in a good state $\mathrm{k}, \mathrm{k}=0$.

$\delta_{\mathrm{j}} \quad$ lot being proportion defective in a degrade state $\mathrm{j}$. $\mathrm{j} \neq \mathrm{k}$

$\mu_{\mathrm{k}} \quad$ mean rate of change per lot from good state $\mathrm{k}$ to bad state $\mathrm{j}$.

$\mu_{\mathrm{j}} \quad$ mean rate of change per lot from degrade state $\mathrm{j}$ to good state $\mathrm{k}$.

c acceptance number.

$\mathrm{E}(\mathrm{C}) \quad$ average cost of a good unit.

$\mathrm{G}$ good units received after inspection to the customer.

$\mathrm{t}$ criterion for switching to normal inspection.

$\mathrm{s} \quad$ criterion for switching to tightened inspection.

$\mathrm{Pa}_{\mathrm{k}} \quad$ probability of accepting the lot when the fraction defective is in state $\mathrm{k}$ under theTNT plan. 
$\operatorname{Pr}_{\mathrm{k}} \quad$ probability of rejecting the lot when the fraction defective is in state $\mathrm{k}$.

$\mathrm{Pa}_{\mathrm{j}} \quad$ probability of accepting the lot when the fraction defective is in state $\mathrm{j}$ under the TNT plan.

$\operatorname{Pr}_{\mathrm{j}} \quad$ probability of rejecting the lot when the fraction defective is in state $\mathrm{j}$.

TFC Total failure costs.

APC Appraisal costs.

MC Manufacturing costs.

Determination and implementation of optimal parameters for TNT-( $n_{1}, n_{2}$, c) with SSP under the conditions of Poisson distribution:

Designing of TNT with SSP as reference plan under the conditions of Poisson distribution has a prime objective to obtain an optimum combination of parameters $\left(\boldsymbol{n}_{1}, \boldsymbol{n}_{2}, \boldsymbol{c}\right)$ so that the scheme can protect both consumer as well as producer. This can be achieved by specifying $\left(\delta_{\mathrm{k}}, \alpha, \delta_{\mathrm{j}}, \beta\right)$ and applying the conditions $P_{a}\left(\delta_{\mathrm{k}}\right)=1-\alpha$ and $P_{a}\left(\delta_{\mathrm{j}}\right)=\beta$. Since the above conditions may not be true for all the situations as the parameters $n_{1}, n_{2}$ and $c$ are integer random variables. Hence, these conditions may be modified as $P_{a}\left(p_{1}\right) \geq 1-\alpha$ and $P_{a}\left(p_{2}\right) \leq \beta$. According to Soundararajan and Devaraj Arumainayagam [15] indicates that the parameters of QSS-r $(\mathrm{r}=1,2,3$ and 4) for defects using Poisson model for given values of $p_{1}(\alpha=0.05)$ and $p_{2}(\beta=0.10)$ satisfying the conditions (i) $\mathrm{P}_{\mathrm{r}}$ (accepting the lot of quality $\left.\mathrm{p} \leq \mathrm{p}_{1}\right) \geq 1-\alpha$, and (ii) $P_{r}$ (rejecting the lot of quality $\left.p \geq p_{2}\right) \leq \beta$. This can be obtained using the search procedure in this paper for the proposed plan and tabulated in Table.1. Here the excellent quality is considered as good state and the quality next to that is considered as the degraded state so the probability of rejecting the second quality by the consumer is less than $10 \%$ or more. Thus the plan protects the producer which in turn the consumer is also protected as the sample size increases.

The parameters of proposed sampling schemes using the Table.1 can be obtained by applying a search procedure as follows,

i. Given the lot size $\mathrm{N}, \mathrm{n}_{1}, \mathrm{n}_{2}, \mathrm{t}, \mathrm{s}$ and $\mathrm{c}=0$.

ii. Compute the probability of acceptance of lot under normal and tightened inspection.

iii. Probability of acceptance of lots for good and degrade state under each inspection is determined using SSP as the reference plan under the conditions of Poisson distribution.

iv. Then it helps to determine the probability of acceptance of lots under TNT scheme.

The above procedure is described in the illustration 3.1

\section{Illustration 3.1}

Let us assume that the industry is manufacturing spare parts of automobile component in which the production is a continuous process may have two states $\mathrm{k}$ and $\mathrm{j}$ where in inspection lot during switching process the one is good state $\delta_{\mathrm{k}}=0.01$ and the other proportion defective are considered as the degraded state $\delta_{\mathrm{j}}=0.10$. Given the lot size $\mathrm{N}=1000$, the number of products to be inspected is $\mathrm{n}_{1}=20, \mathrm{n}_{2}=5$, the tightened lot size $\mathrm{t}=5$ and the normal lot size $\mathrm{s}=4$ and having acceptance number $\mathrm{c}=0$. Suppose that, the required plan should have the strength $\delta_{k}=0.01, \alpha=0.05, \delta_{j}=0.10$ and $\beta=$ 0.10 to obtain an optimum plan of TNT scheme so that the probability of acceptance of lots for good and degrade state under each inspection is determined using SSP as the reference plan under the conditions of Poisson distribution is given in Table 1.

Table. 1 The probability of acceptance of lot using single sampling plan

\begin{tabular}{|c|c|c|c|c|c|c|c|c|}
\hline $\mathbf{N}$ & $\mathbf{n}_{1}$ & $\mathbf{n}_{2}$ & $\mathbf{t}$ & $\mathbf{s}$ & $\begin{array}{c}\mathbf{P}_{\mathrm{k}} \\
\text { normal }\end{array}$ & $\begin{array}{c}\mathbf{P}_{\mathbf{k}} \\
\text { tightened }\end{array}$ & $\begin{array}{c}\mathbf{P}_{\mathbf{j}} \\
\text { normal }\end{array}$ & $\begin{array}{c}\mathbf{P}_{\mathbf{j}} \\
\text { tightened }\end{array}$ \\
\hline 1000 & $\mathbf{2 0}$ & $\mathbf{5}$ & $\mathbf{5}$ & $\mathbf{4}$ & $\mathbf{0 . 8 3}$ & $\mathbf{0 . 9 5}$ & $\mathbf{0 . 9 5}$ & $\mathbf{0 . 8 2}$ \\
\hline 1200 & $\mathbf{2 0}$ & $\mathbf{6}$ & $\mathbf{5}$ & $\mathbf{4}$ & $\mathbf{0 . 8 3}$ & $\mathbf{0 . 9 4}$ & $\mathbf{0 . 9 4}$ & $\mathbf{0 . 8 2}$ \\
\hline 1000 & 22 & 7 & $\mathbf{5}$ & $\mathbf{4}$ & $\mathbf{0 . 8 1}$ & $\mathbf{0 . 9 4}$ & $\mathbf{0 . 9 2}$ & $\mathbf{0 . 8 0}$ \\
\hline
\end{tabular}

The optimum TNT plan obtained in illustration 3.1 can be implemented as follows,

1. Start with tightened inspection with SSP under the conditions of Poisson distribution by inspecting every lot submitted in order with sample size $n=20$ and acceptance number 0 .

2. If $\mathrm{t}=5$ lots are accepted during tightened inspection, then switch to normal inspection. During normal inspection, inspect the lots using SSP with the sample size $n=20$ and acceptance number 0 .

3. If a lot is rejected during normal inspection $s$ then switch to tightened inspection and repeat step 1 .

Procedure for the economic designing of TNT scheme $\left(n_{1}, n_{2}, c\right)$ for the inspection of destructive and non-destructive of a lot:

According to Hald [7] stated that in a lot-by-lot sampling inspection by attributes the product is divided into inspection lots or several samples are drawn at random from each lot and the decision to sentence the lot is based on the rules imposed by the sampling plan. If the output of a production process is a continuous stream it is difficult to define a unit of product such as textile, paper and wire and for complex equipment. To overcome this it is natural to count the number of defects per running unit such as volume, length, time and weight. The quality of a lot is defined as the average number of defects per unit. An inspection lot like $t$ and $\mathrm{s}$ is not same as a production lot, shipping lot or an order lot. It is required that inspection lots be homogeneous. The importance of sampling inspection theory lies in the use of random sampling and decision rules is carried out which makes it possible in calculating probability of acceptance for lots of specified quality in advance. 
Inspection allows information on lot quality indeed necessary for every industry and supplier as the lot quality varies and acceptance of defective items is costly it paves way to correct his process if necessary. A sampling plan operates on series of lots of varying quality will be sorted into acceptable and non-acceptable lots. The non-acceptable lots are to be concentrated more for the improvement on this rejected lots. The rejected lots are returned to the supplier should be of economic consequence for him induced to take corrective actions to improve his production process and in rectifying inspection the rejected lots are totally inspected and defective items corrected or replaced by good items.

There are various kinds of inspection in analyzing an inspection problem: rectifying and non-rectifying, destructive and non-destructive. Inspection may take place at different stages of the production process such as (i) inspection of lots received from the supplier before used by the consumer's production process called as receiving inspection, (ii) inspection of lots formed from the running production say an hour's production called process inspection and (iii) inspection of lots before dispatch to the customer called final inspection.

In the inspection of non-destructive items, rejected lots are sorted but not scrapped or reprocessed. There may be possibilities exists in which the rejection means scrapping, reworking and downgrading. Resubmission of rejected lots is made only after the removal, correction or replacement of defective items called as resubmitted lot. The various costs associated with defects discovered before and after the product has been shipped to the customers. The costs are of two types internal and external costs regarding failure include waste, rework costs, returns of rejected lots plans for quality, reliability, operations, production, and inspection in case of non-destructive product.

Manufacturing costs includes the cost of the direct material, factory overhead charges and wages of labor become a part of the finished product. Appraisal costs incurred includes verification, quality audits and supplier rating to find the degree of conformance to the satisfactory level evaluated by the dealer and customer of purchased materials, products, and services to ensure that they conform to the standard. These quality cost allows an organization to prevent from poor quality to the extent and to determine savings by implementing process improvement.

\section{Procedures for the evaluation of cost function:}

The economic sampling plan is found by the following mathematical model:
Objective function is to

Minimize $\mathrm{E}(\mathrm{C})$

Subject to $\mathrm{Pa}\left(\delta_{\mathrm{k}}\right) \geq 1-\alpha$

$$
\operatorname{Pa}\left(\delta_{\mathrm{j}}\right) \leq \beta
$$

and the non-negative constraints are

$\mathrm{n}_{1}, \mathrm{n}_{2} \geq 1, \quad \mathrm{c}>0, \mathrm{t}, \mathrm{s}>0$ and $0<\mathrm{p}<1$.

The optimization problem is to consider the parameters $n_{1}$, $\mathrm{n}_{2}, \mathrm{t}$ and $\mathrm{s}$. The average cost behavior is calculated for each $\mathrm{n}_{1}, \mathrm{n}_{2}$. The algorithm is as Hsu [8, 9] follows and this constructs a model which differs in the following steps.

1. Given the values of $\delta_{\mathrm{k}}, \delta_{\mathrm{j}}, \mu_{\mathrm{k}}$ and $\mu_{\mathrm{j}}$.

2. Set $c=0$. Gradually increase $n_{1}$ and $n_{2}$ by a fixed quantity search for a minimum cost repeating the step with varying lot size $\mathrm{N}, \mathrm{n}_{2}$ and keeping $\mathrm{n}_{1}, \delta_{\mathrm{k}}, \delta_{\mathrm{j}}$ constant.

3 . When the minimum cost for a given $\mathrm{c}$ indicates that the minimum point for $\mathrm{n}_{1}, \mathrm{n}_{2}, \mathrm{t}$, $\mathrm{s}$ and together has been reached, the best plan is obtained for N in TNT scheme.

4. Determine the optimal inspection plan of TNT characterized by $\mathrm{n}_{1}, \mathrm{n}_{2}$ and $\mathrm{c}$ by repeating steps 1,2 and 3 until the minimum $\mathrm{E}(\mathrm{C})$ has been reached.

In this paper executed methods for TNT plans to model an appropriate function for the expected costs having two acceptance probabilities of lots involving switching rules with different state of quality to minimize the expected costs which favors consumer and producer. The various costs are included and their relationship is carried out to show the effectiveness of the TNT plan is given in the following procedures of destructive testing and non-destructive testing of lots.

\section{Procedure of economic designing of TNT plan in the case of destructive testing:}

The cost function assuming that there is a linear relationship between the cost parameter.

Manufacturing Costs is given by

$$
M C=N C_{m}(t+s)
$$

Appraisal Costs: The states $\delta_{\mathrm{k}}$ and $\delta_{\mathrm{j}}$ assuming the prior probabilities as (1- $\alpha)$ and $\beta$ and $(N-n) p$ refers to the average number of units shipped to the buyer without inspection (passed).

$$
A P C=\left(t n_{1}+s n_{2}\right) C_{i}+C_{k}
$$

Total Failure Costs:

$T F C=\left(N(t+s)-\left(t n_{1}+s n_{2}\right)\right)\left(C_{d}\left(\mu_{k} \delta_{k} P a_{k}(1-\alpha)+\mu_{j} \delta_{j} P a_{j} \beta\right)-S\left(\mu_{k} \operatorname{Pr}_{k}+\mu_{j} \operatorname{Pr}_{j}\right)\right)$

After the inspection is over, the lots containing number of good units is shipped to the customer is 


$$
\begin{aligned}
& G=\left(N(t+s)-\left(t n_{1}+s n_{2}\right)\right)\left(1-\mu_{k} \delta_{k}\left(\operatorname{Pr}_{k}\right)+\mu_{j} \delta_{j}\left(\operatorname{Pr}_{j}\right)\right)+ \\
& \left(1-\left(\mu_{k} \operatorname{Pr}_{k}+\mu_{j} \operatorname{Pr}_{j}\right)\right)
\end{aligned}
$$

Total cost in a screening and sampling inspection under TNT plan is

$$
T C=M C+A P C+T F C
$$

Here follows Hsu [8] procedure as the long run minimum average unit cost subject to $\mathrm{n}_{1}, \mathrm{n}_{2}, \mathrm{p}, \mathrm{t}, \mathrm{s}$ is given by

$$
E(C)=\frac{M C+A P C+T F C}{G}
$$

The average cost per unit is calculated by equation (13) are evaluated for obtaining minimum average cost and are given in Tables with numerical illustration and sensitivity analysis 4.1 in section IV.

Procedure of economic designing of TNT plan in the case of non-destructive testing:

\section{Constant Lot size:}

Manufacturing Costs is given by

$$
M C=N C_{m}(t+s)
$$

Appraisal Costs: The states $\delta_{\mathrm{k}}$ and $\delta_{\mathrm{j}}$ assuming the prior probabilities as $(1-\alpha)$ and $\beta$ and $(N-n) p$ refers to the average number of units shipped to the buyer without inspection (passed).

$$
A P C=\frac{C_{k}+C_{i}\left[\begin{array}{l}
\left(t n_{1}+s n_{2}\right)+\left(N(t+s)-\left(t n_{1}+s n_{2}\right)\right)\left(\operatorname{Pr}_{k} \mu_{k}+\right. \\
\left(\operatorname{Pr}_{j} \mu_{j}\right)+\left(N(t+s)-\left(t n_{1}+s n_{2}\right)\right)\left(\mu_{k} \delta_{k} P a_{k}+\mu_{j} \delta_{j} P a_{j}\right)
\end{array}\right]}{1-\left(\mu_{k} \delta_{k}+\mu_{j} \delta_{j}\right)}
$$

Total Failure Costs:

$$
\begin{aligned}
& T F C=C_{d}\left(N(t+s)-\left(t n_{1}+s n_{2}\right)\right)\left(\mu_{k} \delta_{k} P a_{k}(1-\alpha)+\mu_{j} \delta_{j} P a_{j} \beta\right)+ \\
& C_{r}\left[\left(t n_{1}+s n_{2}\right)\left(\mu_{k} \delta_{k}+\mu_{j} \delta_{j}\right)+\left(N(t+s)-\left(t n_{1}+s n_{2}\right)\right)\left(\mathrm{Pr}_{k}\right) \mu_{k} \delta_{k}+\left(\mathrm{Pr}_{j}\right) \mu_{j} \delta_{j}\right]
\end{aligned}
$$

After the inspection is over, the lots containing number of good units is shipped to the customer is

$$
G=N(t+s)
$$

Total cost in a screening and sampling inspection under TNT plan is

$$
T C=M C+A P C+T F C
$$

Here follows Hsu [9] procedure as the long run minimum average unit cost subject to $\mathrm{n}_{1}, \mathrm{n}_{2}, \mathrm{p}, \mathrm{t}, \mathrm{s}$ is given by

$$
E(C)=\frac{M C+A P C+T F C}{G}
$$

The average cost per unit is calculated and evaluated for obtaining minimum average cost and are given in Tables with numerical illustrations and sensitivity analysis 4.2 in section IV.
Procedure of economic designing of TNT plan in the case of non-destructive testing: Variable lot size:

Manufacturing Costs is given by

$$
M C=N C_{m}(t+s)
$$

Appraisal Costs: The states $\delta_{\mathrm{k}}$ and $\delta_{\mathrm{j}}$ assuming the prior probabilities as (1- $\alpha)$ and $\beta$ and $(N-n) p$ refers to the average number of units shipped to the buyer without inspection (passed).

$A P C=C_{k}+C_{i}\left[\begin{array}{l}\left(t n_{1}+s n_{2}\right)+\left(N(t+s)-\left(t n_{1}+s n_{2}\right)\right)\left(\operatorname{Pr}_{k} \mu_{k}+\right. \\ \frac{\left.\operatorname{Pr}_{j} \mu_{j}\right)+\left(N(t+s)-\left(t n_{1}+s n_{2}\right)\right)\left(\mu_{k} \delta_{k} P a_{k}+\mu_{j} \delta_{j} P a_{j}\right)}{1-\left(\mu_{k} \delta_{k}+\mu_{j} \delta_{j}\right)}\end{array}\right]$

Total Failure Costs:

$$
T F C=C_{d}\left(N(t+s)-\left(t n_{1}+s n_{2}\right)\right)\left(\mu_{k} \delta_{k} P a_{k}(1-\alpha)+\mu_{j} \delta_{j} P a_{j} \beta\right)
$$

After the inspection is over, the lots containing number of good units is shipped to the customer is

$$
\begin{aligned}
& G=\left(N(t+s)-\left(t n_{1}+s n_{2}\right)\right)\left(1-\left(\mu_{k} \delta_{k} \operatorname{Pr}_{k}+\mu_{j} \delta_{j} \operatorname{Pr}_{j}\right)\right)+ \\
& \left(t n_{1}+s n_{2}\right)\left(1-\left(\mu_{k} \delta_{k}+\mu_{j} \delta_{j}\right)\right)
\end{aligned}
$$

The shipped discrepant units will be replaced by good and the discrepant units found in sampling and screening process is discarded and not replaced.

Total cost in a screening and sampling inspection under TNT plan is

$$
T C=M C+A P C+T F C
$$

Here follows Hsu [9] procedure as the long run minimum average unit cost subject to $\mathrm{n}_{1}, \mathrm{n}_{2}, \mathrm{p}, \mathrm{t}, \mathrm{s}$ is given by

$$
E(C)=\frac{M C+A P C+T F C}{G}
$$

The Tightened-normal-Tightened plan helps in reduced inspections which automatically signify the minimum average unit cost is safeguard to the customer from accepting the unsatisfactory lot and favors the producer. There may be two states $\mathrm{k}$ and $\mathrm{j}$ in the production process where in inspection lot during switching process the one is good state $\mathrm{k}$ having very least proportion defective and the other proportion defective are considered as the degraded state $\mathrm{j}$. Numerical illustrations and sensitivity analysis 4.3 has been provided in the section IV for the optimal inspection plan that minimizes the average cost. 


\section{RESUltS AND DISCUSSION}

\section{Numerical Illustrations and Sensitivity Analysis 4.1}

Consider the industry is manufacturing automobile spare parts (component) in which the production is a continuous process the sampled items which are taken for inspection as a destructive one. For instance, the pillion handle main tube is an automobile spare part taken to identify its welding strength and thickness which supports the pillion handle component. These descriptive testing items comprise of two types of units- namely usable units and recycling units in the lots manufactured by the company. Usable units are utilized by the company in different lots throughout the manufacturing process of the product. Recycling units are not utilized by the company for the current manufacturing but are used in a different schedule because of its raw material value.

The raw material specification cost for the company with regard to the Pillion Handle Component comprises of the production cost for the raw materials utilized and also the penalty cost for replacing defective units in the manufacturing lots at different stages of manufacturing process. Therefore, it is inferred that since the total material specification cost involves penalty cost for replacement, constant check of the quality of raw materials and finished product by the Quality control department are essential for the component.

The lot of size $\mathrm{N}=1000$ are submitted for inspection in the order of their production process assuming the quality is homogeneous throughout the lot. The inspection is carried on go-no-go basis after the specification is tested by the production engineer. The program manager suggests that the manufacturing cost of pillion handle main tube is $\mathrm{c}_{\mathrm{m}}=$ Rs. 53.78, the cost of inspecting is $\mathrm{c}_{\mathrm{i}}=$ Rs. 0.15 , penalty cost for replacing a defective unit shipped to consumer is $\mathrm{c}_{\mathrm{d}}=$ Rs. 10.44 , cost per inspection and reset the equipment before starting the manufacture the pre-checking is done with $c_{k}=$ Rs. 5.59. The salvage value or scrap cost per unit for the rejected lot is $S=0.11$.

There may be two possible states $\mathrm{k}$ with least proportion defective $\delta_{\mathrm{k}}=0.01$ and $\mathrm{j}$ with allowable maximum proportion defective $\delta_{j}=0.10$ where there are changes in the process fraction defective as it is continuous production of lots in each inspection interval. Observing from the past records there may be transition from one state to another per lot holding average rate of transition $\mu_{\mathrm{k}}=0.09$ and $\mu_{\mathrm{j}}=0.01$. If the sample size $\mathrm{n}$ and the acceptance number $\mathrm{c}$ exceeded as per the SSP reference plan, the measurement is stopped and the lot is rejected. The acceptance and rejection of lot is based on the Tightened-Normal-Tightened plan.
Table.3 Average cost of TNT plan for destructive testing for fixed $n_{1}$ and $n_{2}$ when the lot size $\mathrm{N}=1000$

\begin{tabular}{|c|c|c|c|c|c|c|c|c|}
\hline$n_{1}=20$ & $\mathbf{n}_{2}=5$ & & & & & & & \\
\hline $\mathbf{t}$ & $\mathbf{S}$ & MC & APC & TFC & G & $\mathrm{AC}$ & $\operatorname{Pa}\left(\delta_{k}\right)$ & $\operatorname{Pa}\left(\delta_{j}\right)$ \\
\hline 5 & 4 & 484020 & 23.59 & 76.301 & 8807 & 54.97 & 0.95 & 0.83 \\
\hline 4 & 3 & 376460 & 19.84 & 60.329 & 6853 & 54.948 & 0.95 & 0.87 \\
\hline 3 & 2 & 268900 & 16.09 & 43.662 & 4895 & 54.944 & 0.95 & 0.91 \\
\hline 2 & 1 & 161340 & 12.34 & 26.43 & 2935 & 54.979 & 0.95 & 0.93 \\
\hline$n_{1}=22$ & $n_{2}=6$ & & & & & & & \\
\hline $\mathbf{t}$ & $\mathbf{S}$ & MC & $\mathbf{A P C}$ & TFC & G & AC & $\operatorname{Pa}\left(\delta_{k}\right)$ & $\operatorname{Pa}\left(\delta_{j}\right)$ \\
\hline 5 & 4 & 484020 & 25.69 & 73.436 & 8780 & 55.136 & 0.93 & 0.8 \\
\hline 4 & 3 & 376460 & 21.49 & $\mathbf{5 8 . 3 7 2}$ & 6833 & 55.105 & 0.94 & 0.84 \\
\hline 3 & 2 & 268900 & 17.29 & $\mathbf{4 2 . 4 3 7}$ & 4882 & 55.093 & 0.94 & 0.89 \\
\hline 2 & 1 & 161340 & 13.09 & 25.776 & 2927 & 55.126 & 0.94 & 0.92 \\
\hline
\end{tabular}

From the Table. 3 it is observed that the sampling plans, $\mathrm{n}_{1}=20, \mathrm{n}_{2}=5$ with varying $\mathrm{t}$ and $\mathrm{s}$ lots are optimum satisfying the risks. But the suitable optimal plan is $\mathrm{N}=1000$, $\mathrm{n}_{1}=20, \mathrm{n}_{2}=5, \mathrm{t}=3$ and $\mathrm{s}=2$ and their minimum average cost is Rs.54.944 satisfying $\mathrm{P}_{\mathrm{a}}\left(\delta_{\mathrm{k}}\right)=0.95$ as well as safeguarding $\mathrm{P}_{\mathrm{a}}\left(\delta_{\mathrm{j}}\right)=0.83$ or $\mathrm{P}_{\mathrm{r}}\left(\delta_{\mathrm{j}}\right)=0.17$ with $\mathrm{MC}=268900, \mathrm{APC}=16.09$, TFC=Rs.43.662 and Good units, $\mathrm{G}=4895$ out of 5000 units. It is well expressed in the figure1.

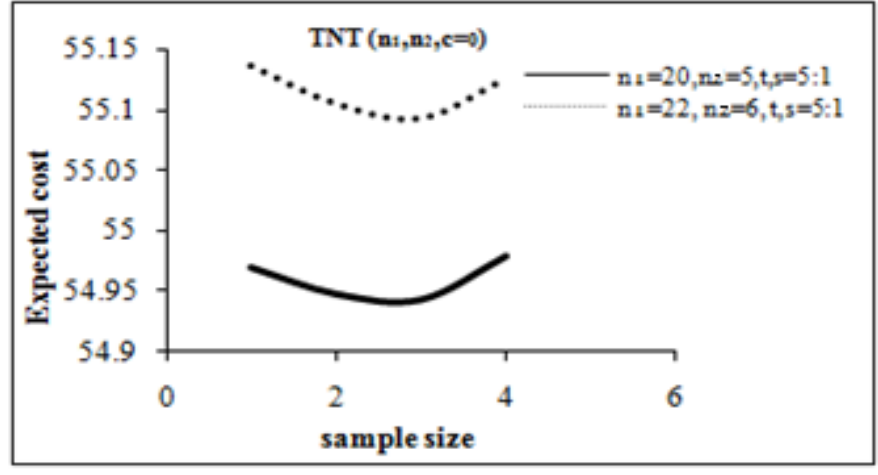

Figure1. Average cost of TNT plan for destructive testing for fixed $n_{1}$ and $n_{2}$ and varied $t$, $s$ lots when $N=1000$

Table. 4 Average cost of TNT plan for destructive testing for varied $n_{1}$ and $\mathrm{n}_{2}$ when the lot size $\mathrm{N}=1000$

\begin{tabular}{|c|c|c|c|c|c|c|c|c|}
\hline$t=5$ & $s=4$ & & & & & & & \\
\hline $\mathbf{n}_{1}$ & $\mathbf{n}_{2}$ & MC & APC & TFC & $\mathbf{G}$ & $\mathbf{A C}$ & $\operatorname{Pa}\left(\delta_{k}\right)$ & $\operatorname{Pa}\left(\delta_{j}\right)$ \\
\hline 20 & 5 & 484020 & 23.59 & 76.301 & 8807 & 54.97 & 0.95 & 0.83 \\
\hline 20 & 7 & 484020 & 24.79 & 72.208 & 8780 & 55.137 & 0.92 & 0.81 \\
\hline 20 & 9 & 484020 & 25.99 & 68.607 & 8756 & 55.291 & 0.9 & 0.79 \\
\hline 20 & 11 & 484020 & 27.19 & 65.469 & 8733 & 55.433 & 0.89 & 0.79 \\
\hline 20 & 13 & 484020 & 28.39 & 62.746 & 8713 & 55.564 & 0.87 & 0.79 \\
\hline 20 & 17 & 484020 & 30.79 & 58.347 & 8677 & 55.795 & 0.84 & 0.8 \\
\hline 20 & 19 & 484020 & 31.99 & 56.575 & 8660 & 55.898 & 0.83 & 0.81 \\
\hline
\end{tabular}


It is observed from the Table. 4 that in the overall sampling plans, $\mathrm{n}_{1}=20, \mathrm{n}_{2}=5, \mathrm{t}=5$ and $\mathrm{s}=4$ and are optimum minimizing producer risk which in turn satisfies consumer's requirements. In particular, the optimal plan is $\mathrm{N}=1000$, $\mathrm{n}_{1}=20, \mathrm{n}_{2}=5, \mathrm{t}=5$ and $\mathrm{s}=4$ and their average cost is Rs. 54.97 satisfying $\mathrm{P}_{\mathrm{a}}\left(\delta_{\mathrm{k}}\right)=0.95$ as well as $\mathrm{P}_{\mathrm{a}}\left(\delta_{\mathrm{j}}\right)=0.83$ or $\mathrm{P}_{\mathrm{r}}\left(\delta_{\mathrm{j}}\right)=0.17$ with Good units, $\mathrm{G}=8807$ is well exposes in the figure 2 for fixed $t$ and $s$.

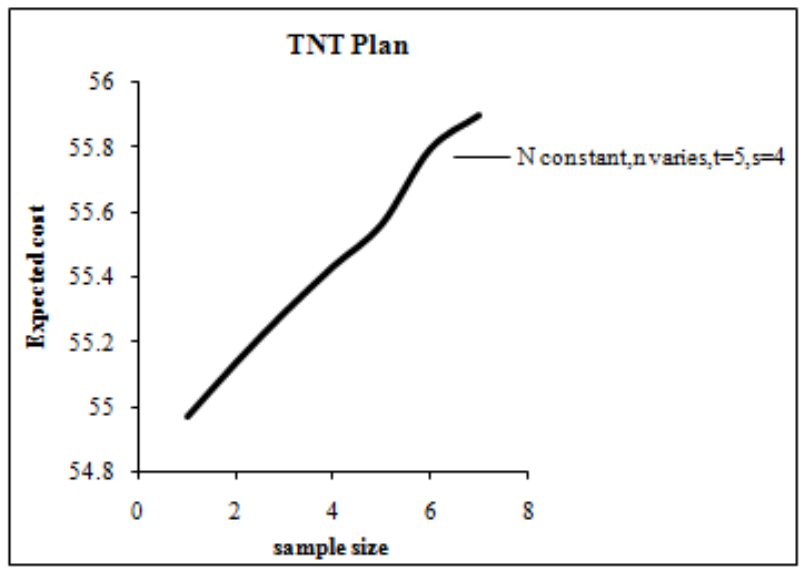

Figure.2 Average cost of TNT plan for destructive testing for varied $n_{1}$ and $n_{2}$ when the lot size $N=1000$

Table.5 Average cost of TNT plan for destructive testing for varied lot size $\mathrm{N}$ and fixed $\mathrm{n}_{1}=20, \mathrm{n}_{2}=5$, $\mathrm{t}$ and $\mathrm{s}$

\begin{tabular}{|c|c|c|c|c|c|c|c|c|c|}
\hline $\mathrm{N}$ & $\mathrm{t}$ & $\mathrm{s}$ & $\mathrm{Pa}\left(\delta_{\mathrm{k}}\right)$ & $\mathrm{Pa}\left(\delta_{\mathrm{j}}\right)$ & $\mathrm{MC}$ & $\mathrm{APC}$ & $\mathrm{TFC}$ & $\mathrm{G}$ & $\mathrm{AC}$ \\
\hline 1000 & 5 & 4 & 0.95 & 0.83 & 484020 & 23.59 & 76.301 & 8807 & 54.97 \\
\hline 1200 & 5 & 4 & 0.95 & 0.83 & 580824 & 23.59 & 91.767 & 10592 & 54.846 \\
\hline 1400 & 5 & 4 & 0.95 & 0.83 & 677628 & 23.59 & 107.23 & 12377 & 54.758 \\
\hline 1600 & 5 & 4 & 0.95 & 0.83 & 774432 & 23.59 & 122.7 & 14163 & 54.692 \\
\hline 1800 & 5 & 4 & 0.95 & 0.83 & 871236 & 23.59 & 138.17 & 15948 & 54.641 \\
\hline 2000 & 5 & 4 & 0.95 & 0.83 & 968040 & 23.59 & 153.63 & 17733 & 54.6 \\
\hline 2200 & 5 & 4 & 0.95 & 0.83 & 1064844 & 23.59 & 169.1 & 19518 & 54.567 \\
\hline
\end{tabular}

As discussed in Table.5 all the sampling plans for fixed $\mathrm{n}_{1}, \mathrm{n}_{2}, \mathrm{t}$ and $\mathrm{s}$ under varied lot size $\mathrm{N}$ are optimum. But the program managers selects the optimum plan with minimum average cost $\mathrm{AC}=\mathrm{Rs} .54 .567$ that minimizes the risks of producer as well as consumer. Figure 3 picturize that the inspection is carried out on fixed $\mathrm{n}_{1}, \mathrm{n}_{2}, \mathrm{t}$ and $\mathrm{s}$ and the average cost of TNT plan decreases as $\mathrm{N}$ increases. Their various costs are $\mathrm{MC}=\mathrm{Rs} .1064844, \quad \mathrm{APC}=\mathrm{Rs} .23 .59$, TFC=Rs.169.1 and Good units, $\mathrm{G}=19518$ out of 19800 units.

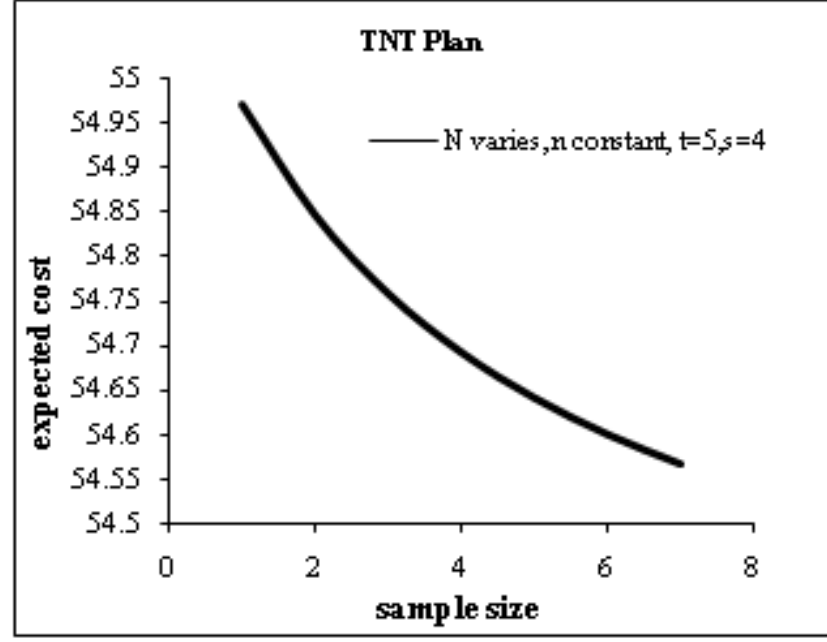

Figure3. Average Cost of TNT plan for destructive testing for varied lot size $N$ and fixed $n_{1}, n_{2}$, tand $s$

Numerical Illustrations and Sensitivity Analysis 4.2

Consider the industry is manufacturing automobile spare parts (component) in which the production is a continuous process the sampled items which are taken for inspection as a non-destructive one. For instance, the pillion handle main tube is an automobile spare part conducting magnetic particle testing can be considered as a combination of two nondestructive test for magnetic flux leakage testing and visual testing. For detecting surface and shallow subsurface discontinuities in the handle main tube to identify a leak evaluated to determine the properties of a material, component or system without causing damage. The lot size $\mathrm{N}=1000$ is constant throughout the production are submitted for inspection in the order of their production process assuming the quality is homogeneous throughout the lot. The inspection is carried on go-no-go basis after the specification is tested by the production engineer. The program manager suggests that the manufacturing cost of pillion handle main tube is $c_{m}=$ Rs. 53.78, the cost of inspecting is $c_{i}=$ Rs.0.15, penalty cost for replacing a discrepancy unit shipped to consumer is $c_{d}=$ Rs. 10 , cost per inspection and reset the equipment before starting the manufacture the pre-checking is done with $c_{k}=R s .4 .7$. The corrective cost of a discrepant unit during the sampling and the screening process is $\mathrm{c}_{\mathrm{r}}=$ Rs. 5.59.

There may be two states $\mathrm{k}$ and $\mathrm{j}$ where there are changes in the process fraction defective is continuous as the lots are produced in each inspection interval from the past records as dictated in the section III. There may be transition from one state to another per lot. The acceptance and rejection of the lot is based on as Tightened-Normal-Tightened plan. 
Table.6 Average cost of TNT plan for non-destructive testing for fixed $\mathrm{n}_{1}$

\begin{tabular}{|c|c|c|c|c|c|c|c|c|}
\hline $\mathbf{t}$ & $\mathbf{S}$ & MC & APC & TFC & G & $\mathbf{A C}$ & $\operatorname{Pa}(\boldsymbol{\delta} \mathbf{k})$ & $\mathrm{Pa}(\delta \mathbf{j})$ \\
\hline 5 & 4 & 484020 & 20.297 & 82.931 & 9000 & 53.791 & 0.95 & 0.83 \\
\hline 4 & 3 & 376460 & 17.199 & 64.935 & 7000 & 53.792 & 0.95 & 0.871 \\
\hline 3 & 2 & 268900 & 14.564 & 46.626 & 5000 & 53.792 & 0.95 & 0.907 \\
\hline 2 & 1 & 161340 & 12.301 & 28.064 & 3000 & 53.793 & 0.95 & 0.935 \\
\hline $\mathbf{n}_{1}=22$ & $n_{2}=6$ & & & & & & & \\
\hline $\mathbf{t}$ & $\mathbf{S}$ & MC & APC & TFC & G & $\mathbf{A C}$ & $\operatorname{Pa}(\delta \mathbf{k})$ & $\mathrm{Pa}(\delta \mathrm{j})$ \\
\hline 5 & 4 & 484020 & 22.628 & 81.537 & 9000 & 53.792 & 0.93 & 0.798 \\
\hline 4 & 3 & 376460 & 18.925 & 63.975 & 7000 & 53.792 & 0.94 & 0.843 \\
\hline 3 & 2 & 268900 & 15.807 & 46.018 & $\mathbf{5 0 0 0}$ & 53.792 & 0.94 & 0.886 \\
\hline 2 & 1 & 161340 & 13.172 & 27.734 & 3000 & 53.794 & 0.94 & 0.921 \\
\hline
\end{tabular}

From the Table.6 it is revealed that the overall sampling plans, $\mathrm{n}_{1}=20, \mathrm{n}_{2}=5$ with varying $\mathrm{t}$ and $\mathrm{s}$ lots are optimum satisfying the risks. But the suitable optimal plan is $\mathrm{N}=1000, \mathrm{n}_{1}=20, \mathrm{n}_{2}=5, \mathrm{t}=5$ and $\mathrm{s}=4$ and their average cost is Rs.53.791 satisfying $\mathrm{P}_{\mathrm{a}}\left(\delta_{\mathrm{k}}\right)=0.95$ and $\mathrm{P}_{\mathrm{a}}\left(\delta_{\mathrm{j}}\right)=0.83$ or $\mathrm{P}_{\mathrm{r}}\left(\delta_{\mathrm{j}}\right)=0.17 \quad$ with $\quad \mathrm{MC}=\mathrm{Rs} .484020, \quad \mathrm{APC}=\mathrm{Rs} .20 .297$, $\mathrm{TFC}=$ Rs. 82.931 and Good units, $\mathrm{G}=9000$. It is well displayed in the figure4.

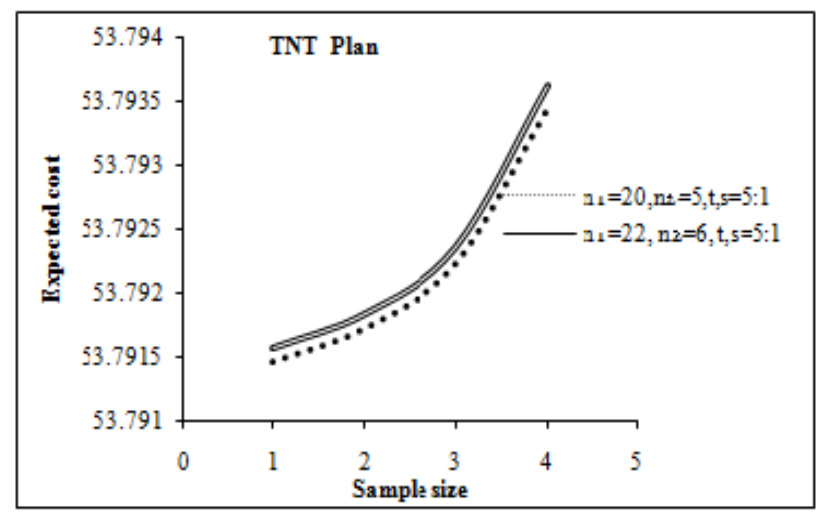

Figure4. Average Cost of TNT plan for non-destructive testing for fixed $n_{l}$ and $n_{2}$ when the lot size $N=1000$

It is observed from the Table.7 that the sampling plan $\mathrm{n}_{1}=20, \mathrm{n}_{2}=5, \mathrm{t}=5$ and $\mathrm{s}=4$ is optimum satisfying the risks achieving the minimum average cost per unit is Rs. 53.791 satisfying $\mathrm{P}_{\mathrm{a}}\left(\delta_{\mathrm{k}}\right)=0.95$ as well as $\mathrm{P}_{\mathrm{a}}\left(\delta_{\mathrm{j}}\right)=0.83$ or $\mathrm{P}_{\mathrm{r}}\left(\delta_{\mathrm{j}}\right)=0.17$ with Good units, $G=9000$ for the constant lot size from the production process and varying sample size is well exposes in the figure 5 for fixed $t$ and $s$ lots.
Table.7 Average Cost of TNT plan for non-destructive testing for varied $\mathrm{n}_{1}$

\begin{tabular}{|c|c|c|c|c|c|c|c|c|}
\hline$t=5$ & $s=4$ & & & & & & & \\
\hline$n_{1}$ & $\mathbf{n}_{2}$ & MC & APC & TFC & G & $\mathrm{AC}$ & $\operatorname{Pa}\left(\delta_{k}\right)$ & $\operatorname{Pa}\left(\delta_{j}\right)$ \\
\hline 20 & 5 & 484020 & 20.297 & 82.931 & 9000 & 53.791 & 0.95 & 0.83 \\
\hline 22 & 6 & 484020 & 22.628 & 81.537 & 9000 & 53.792 & 0.93 & 0.798 \\
\hline 24 & 7 & 484020 & 25.027 & 80.1 & 9000 & 53.792 & 0.92 & 0.766 \\
\hline 26 & 8 & 484020 & 27.488 & 78.621 & 9000 & 53.792 & 0.91 & 0.737 \\
\hline 28 & 9 & 484020 & 30.008 & 77.104 & 9000 & 53.792 & 0.89 & 0.708 \\
\hline 30 & 10 & 484020 & 32.579 & 75.554 & 9000 & 53.792 & 0.88 & 0.682 \\
\hline 32 & 11 & 484020 & 35.193 & 73.976 & 9000 & 53.792 & 0.86 & 0.657 \\
\hline
\end{tabular}

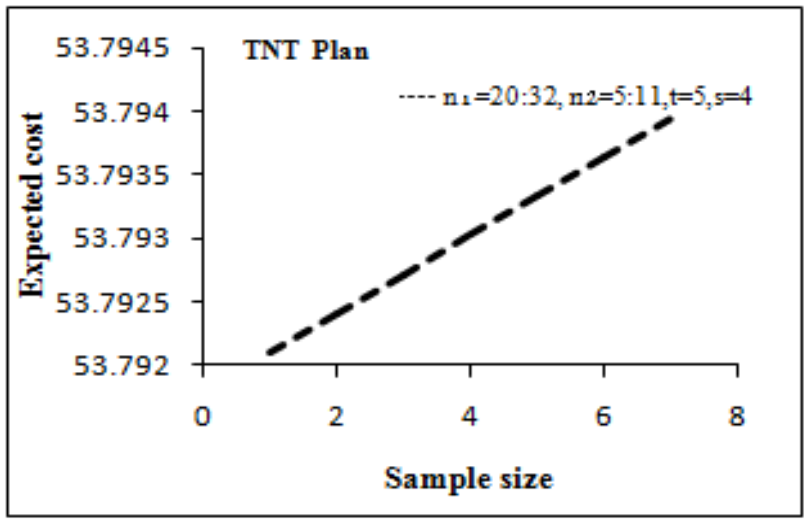

Figure5. Average Cost of TNT plan for non-destructive testing for varied $n_{1}$ and $n_{2}$ when the lot size $N=1000$

As referred in Table.8, all the sampling plans for fixed $\mathrm{n}_{1}, \mathrm{n}_{2}, \mathrm{t}$ and $\mathrm{s}$ under varied lot size $\mathrm{N}$ are optimum. Here the program manager consider better to choose the optimal plan as $\mathrm{N}=2200, \mathrm{n}_{1}=20, \mathrm{n}_{2}=5, \mathrm{t}=5$ and $\mathrm{s}=4$ and their average cost is Rs.53.791with good units, $G=19800$ is well expressed in figure6 shows that as the lot size increases the cost remains same for fixed sample size in the case of nondestructive testing items.

Table. 8 Average cost of TNT plan for non-destructive testing for varied lot size $\mathrm{N}$ and fixed $\mathrm{n}_{1}=20, \mathrm{n}_{2}=5$, $\mathrm{t}$ and $\mathrm{s}$

\begin{tabular}{|c|c|c|c|c|c|c|c|c|c|}
\hline $\mathrm{N}$ & $\mathrm{t}$ & $\mathrm{s}$ & $\mathrm{Pa}\left(\delta_{\mathrm{k}}\right)$ & $\mathrm{Pa}\left(\delta_{\mathrm{j}}\right)$ & $\mathrm{MC}$ & $\mathrm{APC}$ & $\mathrm{TFC}$ & $\mathrm{G}$ & $\mathrm{AC}$ \\
\hline 1000 & 5 & 4 & 0.95 & 0.83 & 484020 & 20.297 & 82.931 & 9000 & 53.791 \\
\hline 1200 & 5 & 4 & 0.95 & 0.83 & 580824 & 22.518 & 99.737 & 10800 & 53.791 \\
\hline 1400 & 5 & 4 & 0.95 & 0.83 & 677628 & 24.739 & 116.54 & 12600 & 53.791 \\
\hline 1600 & 5 & 4 & 0.95 & 0.83 & 774432 & 26.96 & 133.35 & 14400 & 53.791 \\
\hline 1800 & 5 & 4 & 0.95 & 0.83 & 871236 & 29.181 & 150.15 & 16200 & 53.791 \\
\hline 2000 & 5 & 4 & 0.95 & 0.83 & 968040 & 31.402 & 166.96 & 18000 & 53.791 \\
\hline 2200 & 5 & 4 & 0.95 & 0.83 & 1064844 & 33.623 & 183.76 & 19800 & 53.791 \\
\hline
\end{tabular}




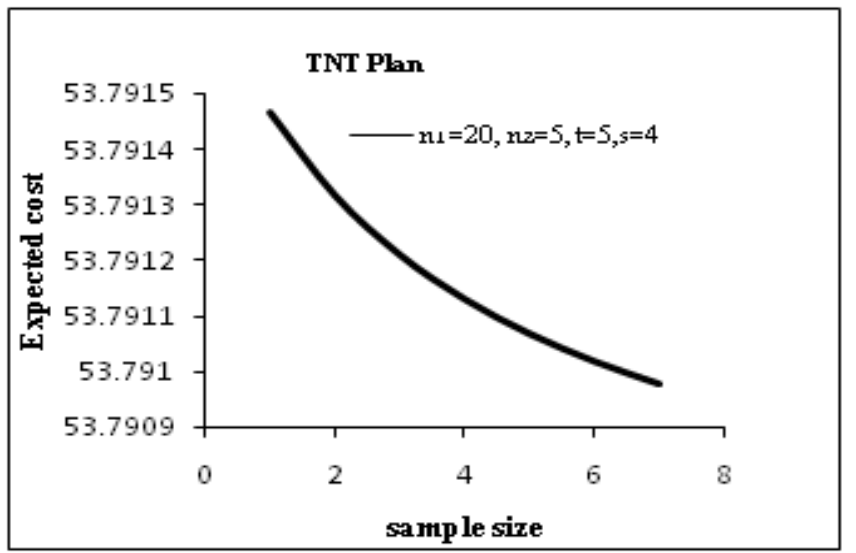

Figure6. Average Cost of TNT plan for non-destructive testing for varied lot size $N$ and fixed $n_{1}, n_{2}$, $t$ and $s$

As discussed in Table. 9 the sampling plan $\mathrm{n}_{1}=20$, $\mathrm{n}_{2}=5, \mathrm{t}=5$ and $\mathrm{s}=4$ for fixed $\mathrm{N}$ and varied $\mathrm{n}_{2}$ are optimum. Thus the program managers selects the optimum plan with minimum average cost is $\mathrm{AC}=\mathrm{Rs}$. 53.791 satisfying $\mathrm{P}_{\mathrm{a}}\left(\delta_{\mathrm{k}}\right)=0.95$ and $\mathrm{P}_{\mathrm{a}}\left(\delta_{\mathrm{j}}\right)=0.83$ or $\mathrm{P}_{\mathrm{r}}\left(\delta_{\mathrm{j}}\right)=0.17$ with $\mathrm{MC}=484020$, APC=Rs. 20.297, TFC=Rs. 82.932 and Good units, $\mathrm{G}=9000$ that minimizes the risks of producer which in turn satisfies consumer's requirement. Figure 7 picturizes that if the inspection is carried out on fixed $\mathrm{n}_{1}, \mathrm{t}, \mathrm{s}$ and varied $\mathrm{n}_{2}$ then the average cost of TNT plan increases as the sample size increases.

Table.9 Average cost of TNT plan for non-destructive testing for varied $\mathrm{n}_{2}$ and fixed lot size $\mathrm{N}, \mathrm{n}_{1}=20$, $\mathrm{t}$ and $\mathrm{s}$.

\begin{tabular}{|c|c|c|c|c|c|c|c|c|c|c|}
\hline $\mathrm{N}$ & $\mathrm{n}_{2}$ & $\mathrm{t}$ & $\mathrm{s}$ & $\mathrm{Pa}\left(\boldsymbol{\delta}_{\mathrm{k}}\right)$ & $\mathrm{Pa}\left(\boldsymbol{\delta}_{\mathrm{j}}\right)$ & $\mathrm{MC}$ & $\mathrm{APC}$ & $\mathbf{T F C}$ & $\mathrm{G}$ & $\mathrm{AC}$ \\
\hline 1000 & $\mathbf{5}$ & $\mathbf{5}$ & $\mathbf{4}$ & $\mathbf{0 . 9 5}$ & $\mathbf{0 . 8 3}$ & $\mathbf{4 8 4 0 2 0}$ & $\mathbf{2 0 . 2 9 7}$ & $\mathbf{8 2 . 9 3 2}$ & $\mathbf{9 0 0 0}$ & $\mathbf{5 3 . 7 9 1}$ \\
\hline 1000 & $\mathbf{6}$ & $\mathbf{5}$ & $\mathbf{4}$ & $\mathbf{0 . 9 4}$ & $\mathbf{0 . 8 1 7}$ & $\mathbf{4 8 4 0 2 0}$ & $\mathbf{2 1 . 8 9 4}$ & $\mathbf{8 1 . 9 3 1}$ & $\mathbf{9 0 0 0}$ & $\mathbf{5 3 . 7 9 2}$ \\
\hline 1000 & 7 & $\mathbf{5}$ & 4 & $\mathbf{0 . 9 2}$ & $\mathbf{0 . 8 0 7}$ & $\mathbf{4 8 4 0 2 0}$ & $\mathbf{2 3 . 4 0 8}$ & $\mathbf{8 0 . 9 8 6}$ & $\mathbf{9 0 0 0}$ & $\mathbf{5 3 . 7 9 2}$ \\
\hline 1000 & $\mathbf{8}$ & $\mathbf{5}$ & $\mathbf{4}$ & $\mathbf{0 . 9 1}$ & $\mathbf{0 . 8}$ & $\mathbf{4 8 4 0 2 0}$ & $\mathbf{2 4 . 8 3 8}$ & $\mathbf{8 0 . 0 9 8}$ & $\mathbf{9 0 0 0}$ & $\mathbf{5 3 . 7 9 2}$ \\
\hline 1000 & $\mathbf{9}$ & $\mathbf{5}$ & $\mathbf{4}$ & $\mathbf{0 . 9}$ & $\mathbf{0 . 7 9 5}$ & $\mathbf{4 8 4 0 2 0}$ & $\mathbf{2 6 . 1 8 7}$ & $\mathbf{7 9 . 2 6 5}$ & $\mathbf{9 0 0 0}$ & $\mathbf{5 3 . 7 9 2}$ \\
\hline 1000 & 10 & $\mathbf{5}$ & 4 & $\mathbf{0 . 9}$ & $\mathbf{0 . 7 9 2}$ & $\mathbf{4 8 4 0 2 0}$ & $\mathbf{2 7 . 4 5 7}$ & $\mathbf{7 8 . 4 8 5}$ & $\mathbf{9 0 0 0}$ & $\mathbf{5 3 . 7 9 2}$ \\
\hline
\end{tabular}

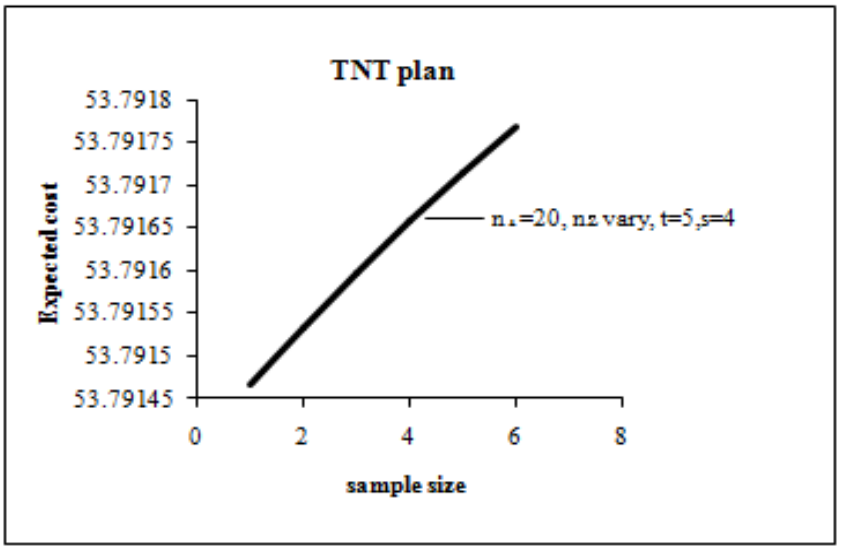

Figure7. Average cost of TNT plan for non-destructive testing for varied $n_{2}$ and fixed lot size $N, n_{1}$, $t$ and $s$.

\section{Numerical Illustration and Sensitivity Analysis 4.3}

The same non-destructive testing is carried out on attribute based for variable lot size $\mathrm{N}$ as illustrated in the numerical illustration 4.2. The acceptance and rejection of the lot is based on as Tightened-Normal-Tightened plan. The cost of an item for various plans is From the Table 10 it is revealed that the overall sampling plans, $\mathrm{n}_{1}=20, \mathrm{n}_{2}=5$ with varying $t$ and $s$ lots are optimum satisfying the risks. But the suitable optimal plan is $\mathrm{N}=2500, \mathrm{n}_{1}=20, \mathrm{n}_{2}=5, \mathrm{t}=5$ and $\mathrm{s}=4$ and their average cost is Rs. 53.811 satisfying $\mathrm{P}_{\mathrm{a}}\left(\delta_{\mathrm{k}}\right)=0.95$ and $\mathrm{P}_{\mathrm{a}}\left(\delta_{\mathrm{j}}\right)=0.93$ or $\mathrm{P}_{\mathrm{r}}\left(\delta_{\mathrm{j}}\right)=0.07$ with $\mathrm{MC}=\mathrm{Rs} .1210050, \mathrm{APC}=$ Rs.51.205, TFC=Rs. 376.792 and Good units, $\mathrm{G}=22495$ out of 22500 units. It is well displayed in the figure8.

Table.10 Average Cost of TNT plan for non-destructive testing for fixed $\mathrm{n}_{1}$ and $\mathrm{n}_{2}$ for variable lot size $\mathrm{N}$

\begin{tabular}{|c|c|c|c|c|c|c|c|}
\hline$n_{1}=\mathbf{2 0}$ & $n_{2}=5$ & $t=5$ & $s=4$ & & & & \\
\hline $\mathbf{N}$ & MC & APC & TFC & G & $\mathrm{AC}$ & $\operatorname{Pa}\left(\delta_{k}\right)$ & $\operatorname{Pa}\left(\delta_{j}\right)$ \\
\hline 1000 & 484020 & 34.547 & 149.738 & 8998 & 53.812 & 0.95 & 0.83 \\
\hline 1500 & 726030 & 40.1 & 225.423 & 13497 & 53.811 & 0.95 & 0.87 \\
\hline 2000 & 968040 & 45.652 & 301.107 & 17996 & 53.811 & 0.95 & 0.91 \\
\hline 2500 & 1210050 & 51.205 & 376.792 & 22495 & 53.811 & 0.95 & 0.93 \\
\hline$n_{1}=22$ & $n_{2}=6$ & $t=5$ & $s=4$ & & & & \\
\hline $\mathbf{N}$ & MC & APC & TFC & G & $\mathrm{AC}$ & $\operatorname{Pa}\left(\delta_{k}\right)$ & $\operatorname{Pa}\left(\delta_{j}\right)$ \\
\hline 1000 & 484020 & 38.529 & 145.654 & 8998 & 53.814 & 0.93 & 0.8 \\
\hline 1500 & 726030 & 45.045 & 219.356 & 13496 & 53.814 & 0.94 & 0.84 \\
\hline 2000 & 968040 & 51.561 & 293.059 & 17995 & 53.813 & 0.94 & 0.89 \\
\hline 2500 & 1210050 & 58.077 & 366.761 & 22494 & 53.813 & 0.94 & 0.92 \\
\hline
\end{tabular}

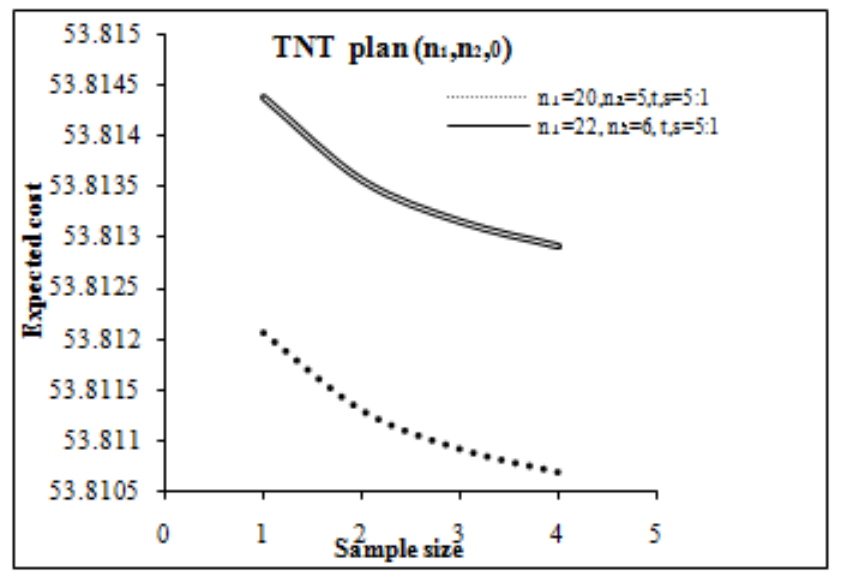

Figure8. Average cost of TNT plan for non-destructive testing for fixed $n_{1}$ and $n_{2}$ for variable lot size $N$ 
It is observed from the Table. 11 that the sampling plan $\mathrm{n}_{1}=20, \mathrm{n}_{2}=5, \mathrm{t}=5$ and $\mathrm{s}=4$ is optimum satisfying the risks achieving the minimum average cost per unit is Rs. 53.812 satisfying $\mathrm{P}_{\mathrm{a}}\left(\delta_{\mathrm{k}}\right)=0.95$ as well as $\mathrm{P}_{\mathrm{a}}\left(\delta_{\mathrm{j}}\right)=0.83$ or $\mathrm{P}_{\mathrm{r}}\left(\delta_{\mathrm{j}}\right)=0.17$ with Good units, $G=8998$ as the shipped discrepant units are replaced for the varied lot size from the production process with varied $\mathrm{n}_{1}, \mathrm{n}_{2}$ and fixed $\mathrm{t}$ and $\mathrm{s}$ lots. As referred in Table 12, the program manager again consider the optimal plan as $\mathrm{N}=1000, \mathrm{n}_{1}=20, \mathrm{n}_{2}=5, \mathrm{t}=5$ and $\mathrm{s}=4$ for fixed $\mathrm{n}_{1}$ and varied $\mathrm{n}_{2}$ under varied lot size $\mathrm{N}$ and their average cost is Rs. 53.812 with good units, $\mathrm{G}=8998$.

As discussed in Table.13, all the sampling plans for fixed $\mathrm{n}_{1}, \mathrm{n}_{2}, \mathrm{t}$ and $\mathrm{s}$ under varied lot size $\mathrm{N}$ are optimum. Here the program manager consider the optimal plan is $\mathrm{N}=$ 2500, $\mathrm{n}_{1}=20, \mathrm{n}_{2}=5, \mathrm{t}=5$ and $\mathrm{s}=4$ and their average cost is Rs.53.811, $\mathrm{MC}=\mathrm{Rs} .1210050, \quad \mathrm{APC}=\mathrm{Rs} .51 .205, \mathrm{TFC}=$ Rs.376.792 with good units, $G=22495$ out of 22500 units that minimizes the risks of producer $\mathrm{P}_{\mathrm{a}}\left(\delta_{\mathrm{k}}\right)=0.95$ which in turn satisfies consumer's requirement is well expressed in figure. 9 shows that as the lot size increases the cost remains same for fixed sample size in the case of non-destructive testing items.

Table.11 Average cost of TNT plan for non-destructive testing for varied $\mathrm{n}_{1}$ and $\mathrm{n}_{2}$ and varied lot size $\mathrm{N}$.

\begin{tabular}{|c|c|c|c|c|c|c|c|c|c|}
\hline $\mathrm{t}=5$ & \multicolumn{2}{|c|}{$\mathrm{S}=4$} & & & & & & & \\
\hline $\mathrm{N}$ & $\mathrm{n}_{1}$ & $\mathrm{n}_{2}$ & MC & APC & TFC & G & AC & $\mathrm{Pa}\left(\delta_{\mathrm{k}}\right)$ & $\mathrm{Pa}\left(\delta_{\mathrm{j}}\right)$ \\
\hline 1000 & 20 & 5 & 484020 & 34.547 & 149.738 & 8998 & 53.812 & 0.95 & 0.83 \\
\hline 1500 & 22 & 6 & 726030 & 45.045 & 219.356 & 13496 & 53.814 & 0.93 & 0.8 \\
\hline 2000 & 24 & 7 & 968040 & 57.611 & 285.127 & 17995 & 53.815 & 0.92 & 0.77 \\
\hline 2500 & 26 & 8 & 1210050 & 72.347 & 347.173 & 22492 & 53.817 & 0.91 & 0.74 \\
\hline
\end{tabular}

Table.12 Average cost of TNT plan for non-destructive testing for fixed $n_{1}=20$ and varied $n_{2}$

\begin{tabular}{|c|c|c|c|c|c|c|c|c|}
\hline $\mathrm{t}=5$ & $\mathrm{~s}=4$ & & & & & & & \\
\hline $\mathrm{N}$ & $\mathrm{n}_{2}$ & $\mathrm{MC}$ & $\mathrm{APC}$ & $\mathrm{TFC}$ & $\mathrm{G}$ & $\mathrm{AC}$ & $\mathrm{Pa}\left(\boldsymbol{\delta}_{\mathrm{k}}\right)$ & $\mathrm{Pa}\left(\boldsymbol{\delta}_{\mathrm{j}}\right)$ \\
\hline 1000 & 5 & 484020 & 34.547 & 149.738 & 8998 & 53.812 & 0.95 & 0.83 \\
\hline 1500 & 6 & 580824 & 39.11 & 177.492 & 10797 & 53.813 & 0.94 & 0.82 \\
\hline 2000 & 7 & 677628 & 44.145 & 204.895 & 12597 & 53.814 & 0.92 & 0.81 \\
\hline 2500 & 8 & 774432 & 49.602 & 232.069 & 14396 & 53.814 & 0.91 & 0.8 \\
\hline
\end{tabular}

Table.13 Average cost of TNT plan for non-destructive testing for fixed $\mathrm{n}_{1}=20, \mathrm{n}_{2}=5$, $\mathrm{t}$ and $\mathrm{s}$.

\begin{tabular}{|c|c|c|c|c|c|c|c|c|c|}
\hline $\mathrm{N}$ & $\mathrm{t}$ & $\mathrm{s}$ & $\mathrm{Pa}\left(\delta_{\mathrm{k}}\right)$ & $\mathrm{Pa}\left(\delta_{\mathrm{j}}\right)$ & $\mathrm{MC}$ & $\mathrm{APC}$ & $\mathrm{TFC}$ & $\mathrm{G}$ & $\mathrm{AC}$ \\
\hline 1000 & 5 & 4 & 0.95 & 0.83 & 484020 & 34.547 & 149.738 & 8998 & 53.812 \\
\hline 1500 & 5 & 4 & 0.95 & 0.83 & 726030 & 40.1 & 225.423 & 13497 & 53.811 \\
\hline 2000 & 5 & 4 & 0.95 & 0.83 & 968040 & 45.652 & 301.107 & 17996 & 53.811 \\
\hline 2500 & 5 & 4 & 0.95 & 0.83 & 1210050 & 51.205 & 376.792 & 22495 & 53.811 \\
\hline
\end{tabular}

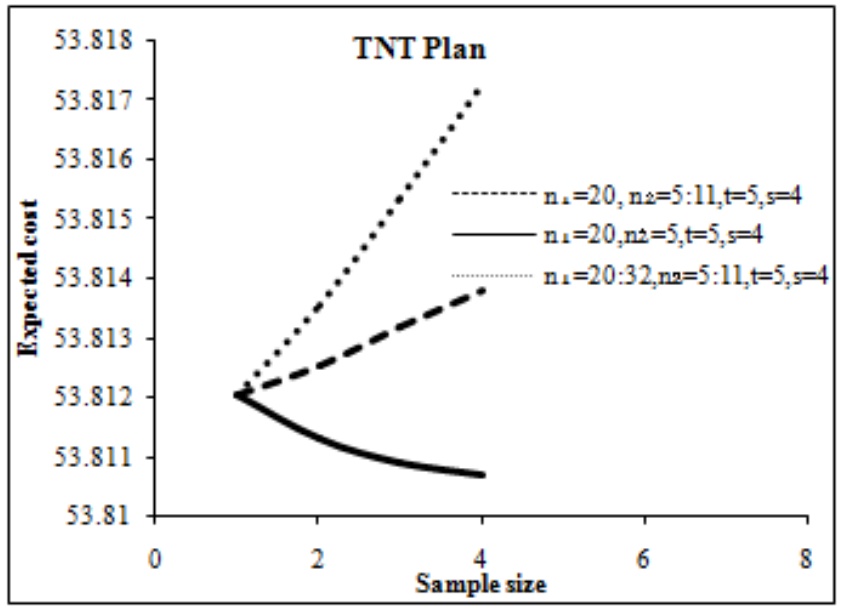

Figure9. Average cost of TNT plan for non destructive testing for varied $n_{1}$ and $n_{2}$

Finally for varied lot size $\mathrm{N}$, the optimal plan is $\mathrm{N}=2500$, $\mathrm{n}_{1}=20, \mathrm{n}_{2}=5, \mathrm{t}=5$ and $\mathrm{s}=4$ and their average cost is Rs. 53.811, $\mathrm{MC}=$ Rs. 1210050, $\mathrm{APC}=$ Rs. 51.205, TFC = Rs. 376.792 with good units, $G=22495$ in the case of non-destructive testing.

\section{CONCLUSION}

This paper attempted to model an appropriate function for the expected costs involving different states of quality. The inspection is carried out based on the Tightened-NormalTightened of rule $\left(\mathrm{n}_{1}, \mathrm{n}_{2}, \mathrm{c}=0\right)$ for both destructive and nondestructive testing in which the cost model has been developed. The sensitivity analysis are performed for the cost parameters of proposed model and tables are provided for the optimal inspection plan which is most economical for the producer and also delivering the quality goods to the consumer at a satisfactory cost. The minimum average cost exists when the parameters change and there is less than $1 \%$ deviation happens in the expected cost. So the cost model suits and also favors the producer and helps the consumer from accepting unsatisfactory level. Even though the cost and sample size $\mathrm{n}$ in some situation of inspection changes to obtain minimum mean cost it protects the consumer as well as the producer. For product characteristics that involve 
safety and non-destructive testing by attributes in varying lot size, large $\mathrm{N}$ is desirable and the expected cost is minimized. It is very economically advantageous to apply this plan in industries for reducing the inspection cost and time.

\section{REFERENCES}

[1]. S. Balamurali, C.H. Jun, "A new system of skip-lot sampling plans having a provision for reducing normal inspection"., Applied Stochastic Models in Business and Industry, Vol. 27, pp.348-363, 2011.

[2]. T.W. Calvin, "TNT zero acceptance number sampling", American Society for Quality Control Technical Conference Transactions, Philadelphia: PA. 1977.

[3]. C.H. Chen, C.Y. Chou, C.C. Kan, "Modified economic production and raw material model with quality loss for conforming product", Journal of Industrial and Production Engineering, Vol. 32, pp.196-203, 2015.

[4]. A.J. Duncan, "Quality Control and Industrial Statistics", Richard D. Irwin, Homewood, Illinois, USA: pp. 7-8, 1986.

[5]. M. S. Fallahnezhad, M. Aslam, "A new economical design of acceptance sampling models using Bayesian inference", Accred Qual Assur, Vol. 18, pp. 187-195, 2013.

[6]. K. Govindaraju, K. Subramani, "Selection of Tightened-NormalTightened system for given values of Acceptable quality level and Limiting quality level", Journal of Applied Statistics, Vol. 19, Issue. 2, pp. 241-250, 1992.

[7]. A. Hald, "Statistical Theory of Sampling Inspection by attributes", Probability and Mathematical Statistics, A series of Monographs and Textbooks, Academic press, London: pp.5-12, 1981.

[8]. J.I.S. Hsu, "A cost model for skip-lot destructive sampling", IEEE Transactions on Reliability, Vol. R-26, Issue. 1, pp.70-72, 1977.

[9]. J.I.S. Hsu, "A cost model for skip-lot non-destructive sampling", IEEE Transactions on Reliability, Vol. R-28, Issue. 4, pp.289-291, 1979.

[10]. MIL-STD 105D, "Sampling Procedures and Tables for Inspection by attributes". U.S. Government Printing Office, Washington, D.C., US, 1963.

[11]. K. Pradeepa Veerakumari, M. Kokila, "Economic Design of Skip-Lot Sampling Plan of Type (SkSP-2) in Reducing Inspection for Destructive sampling", International Journal of Pure and Applied Mathematics, Vol. 117, Issue. 12, pp. $101-111,2018$.

[12]. K. Pradeepa Veerakumari, M. Kokila, "Economic scheme for designing Skip lot sampling plans involving Cost functions using Graphical Evaluation Review Technique", International Journal of Scientific Research in Mathematical and Statistical Sciences, Vol. 5, Issue. 3, pp. 1-5, 2018.

[13]. S.M. Ross, Stochastic processes, 2nd edition. New York: Wiley. 1996.

[14]. E.G. Schilling, D.V. Neubauer. Acceptance Sampling in Quality Control. BocaRaton: CRC Press. Marcel Dekker, New York: pp. 9495, 2008.

[15]. V. Soundararajan, S. D. Arumainaiyagam, "Quick Switching System for Costly and Destructive Testing", Sankhya: The Indian Journal of Statistics, Series B-Part I, Vol. 54, Issue. 1, pp. 1-12, 1992.

[16]. V. Soundararajan, R. Vijayaraghavan, "Construction and Selection of tightened-normal-tightened (TNT) plans", Journal of Quality Technology, Vol. 22, Issue 2, pp. 146-153, 1990.

[17]. K.K. Suresh, S. Balamurali, "Designing of Tightened-NormalTightened (TNT) plans indexed by MAPD". Communication in Statistics - Theory and Methods, Vol.22, Issue 7, pp.2043-2056, 1993.

[18]. D. Senthilkumar, D. Muthuraj, "Construction and selection of tightened-normal-tightened variables sampling scheme of type $\operatorname{TNTVSS}\left(n_{1}, n_{2} ; k\right)$ ", Journal of Applied Statistics, Vol. 37, Issue 3, pp.375-390, 2010

[19]. J.R. Singh, A. Sanvalia, "Single Sampling Plan for Variable Indexed by $A Q L$ and $A O Q L$ with Known Coefficient of Variation", International Journal of Computer Sciences and Engineering, Vol. 5, Issue. 10, pp. 20-25.2017.
[20]. R.S. Walse, G.D. Kurundkar, P. U. Bhalchandra, "A Review: Design and Development of Novel Techniques for Clustering and Classification of Data", International journal of scientific research in Computer science and Engineering, Vol. 6, Issue. 1, pp.19-22.

[21]. Training Course series No.9, "Non-destructive Testing: A Guidebook for Industrial Management and Quality Control Personnel", International Atomic Energy Agency, Vienna: pp.125-150, 1999.

\section{AUTHORS PROFILE}

Ms. Dr. K. Pradeepa Veerakumari pursued M.Sc., and Ph.D., Statistics from Bharathiar University, Coimbatore in 2004 \& 2009. She is currently working as Assistant Professor in Department of Statistics from Bharathiar University, Coimbatore since 2011. She has published more than 20 research papers in reputed international journals including Thomson Reuters (SCI/SCI-E \& Web of Science, Scopus and Google Scholar) and it's also available online. Her main research work focuses on Statistical Quality Control, Neural Network, Bayesian sampling and Expert system.

Ms. M. Kokila is pursuing her Ph.D. in the Department of Statistics, Bharathiar University, Coimbatore. She has published more than three research papers in International journals including Scopus and Google Scholar and is available online.

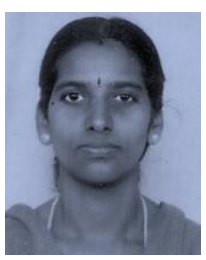

